\title{
Metabolic Impact of Growth Hormone Treatment in Short Children Born Small for Gestational Age
}

\author{
Jan Lebl $^{\mathrm{a}}$ Yael Lebenthal $^{\mathrm{b}}$ Stanislava Kolouskova ${ }^{\mathrm{a}} \quad$ Adam Steensberg $^{\mathrm{c}}$ \\ Kirsten Jøns ${ }^{c}$ Anne-Marie Kappelgaard ${ }^{c}$ Lourdes Ibáñez ${ }^{d}$ Moshe Phillip ${ }^{b}$

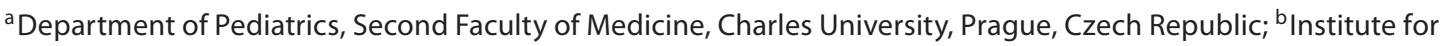 \\ Endocrinology and Diabetes, Schneider Children's Medical Center of Israel and Sackler Faculty of Medicine, \\ Tel-Aviv University, Tel-Aviv, Israel; ' Global Development, Novo Nordisk A/S, Copenhagen, Denmark; \\ ${ }^{d}$ Endocrine Unit, Hospital Sant Joan de Déu, University of Barcelona, Barcelona, and CIBERDEM (CIBER de Diabetes \\ y Enfermedades Metabólicas Asociadas), Instituto de Salud Carlos III, Madrid, Spain
}

\section{Key Words}

Growth hormone $\cdot$ Small for gestational age $\cdot$ Short stature $\cdot$ Metabolic impact

\section{Abstract \\ Background: Growth hormone (GH) treatment in short chil- dren born small for gestational age (SGA) may result in met- abolic changes with potential long-term effects. Methods: 149 short SGA children (mean birth weight $2.0 \pm 0.6 \mathrm{~kg}$, age $5.5 \pm 1.5$ years, height standard deviation score (SDS) -3.1 $\pm 0.6)$ were randomised to: low-dose GH therapy $(0.033 \mathrm{mg} /$ $\mathrm{kg} /$ day) for 2 years; high-dose GH therapy $(0.100 \mathrm{mg} / \mathrm{kg} /$ day $)$ for 1 year, or mid-dose GH therapy $(0.067 \mathrm{mg} / \mathrm{kg} /$ day) for 1 year. Leptin, ghrelin, insulin-like growth factor-I (IGF-I), IGF binding protein-1 (IGFBP-1), lipids, fasting blood glucose and fasting insulin were assessed at baseline, 12 and 24 months. Results: After 1 year of active treatment, GH significantly re- duced serum ghrelin and increased IGF-I SDS and insulin lev- els. Regression analysis showed an inverse correlation be- tween ghrelin and IGF-I SDS ( $p<0.001)$. Leptin and IGFBP-1 also declined (both $p<0.05$ ). Changes in insulin levels re- versed upon discontinuation. Improvements in lipid profile}

were nonsignificant and fasting blood glucose levels remained within the normal range. Conclusion: In short SGA children, ghrelin and leptin reductions associated with $\mathrm{GH}$ treatment may occur through a negative feedback loop of the GH-IGF-I axis. Consequently, via ghrelin and leptin suppression, GH treatment may modify food intake and body composition and potentially improve long-term metabolic outcomes.

Copyright $\odot 2011$ S. Karger AG, Basel

\section{Introduction}

Growth hormone (GH) treatment is an approved therapy for increasing adult height in short children born small for gestational age (SGA) who fail to experience spontaneous postnatal catch-up growth. These children, who account for approximately $10 \%$ of all SGA children, remain short (below -2 standard deviation scores (SDS)) throughout childhood and adulthood if left untreated [13]. In this population, GH treatment increases growth velocity and normalises adult height, and appears to be safe and well tolerated [3-11].

\section{KARGER}

Fax +4161306 1234

E-Mail karger@karger.ch

www.karger.com (c) 2011 S. Karger AG, Basel

$1663-2818 / 11 / 0764-0254 \$ 38.00 / 0$

Accessible online at:

www.karger.com/hrp
Jan Lebl

Department of Pediatrics

Second Faculty of Medicine, Charles University

V Uvalu 84, CZ-150 06 Prague (Czech Republic)

Tel. +420224432 001, E-Mail jan.lebl@lfmotol.cuni.cz 
Although the main aim of GH treatment in short SGA children is to increase height, additional metabolic effects derived from this therapy may modify food intake, appetite and body composition, and potentially result in favourable long-term metabolic benefits. SGA children with spontaneous catch-up growth appear to be at increased risk for type 2 diabetes, hypertension, hyperlipidaemia and adiposity, all of which are, in turn, risk factors for cardiovascular disease [12-14]. The mechanisms underlying these risks are unclear and most likely dependent upon a complex interaction between environmental influences and genetic susceptibility [15]. Several biomarkers have been implicated including leptin, ghrelin and insulin.

Serum levels of leptin, a hormone secreted by adipose tissue [16], are reduced in short children born SGA [17]. GH therapy in short SGA children further decreases leptin levels in a dose-dependent manner, which appears to be correlated with a linear growth response [18]. It has been suggested that GH treatment lowers leptin levels by reducing fat cell mass [18]. Ghrelin is a member of a family of GH secretagogues that stimulate endogenous $\mathrm{GH}$ production in normal adults and children [19]. Ghrelin is primarily secreted from the fundus of the stomach, but also from the hypothalamus [19]. However, only the gastric production of ghrelin may probably be detected. Serum levels of ghrelin are higher in short individuals compared with subjects of normal height, suggesting an inverse relationship between ghrelin levels and the amount of circulating GH $[20,21]$. Surprisingly, many SGA children have low appetite and low weight for their height, despite higher ghrelin levels [22]. Usually higher levels of ghrelin would be expected to increase adiposity in humans by reducing fat utilisation and increasing food intake as a consequence of its effects on stimulating appetite [23]. Yet it can be speculated that at least in some SGA children, there may exist a certain form of ghrelin resistance.

Insulin resistance and subsequent hyperinsulinaemia are common features in SGA children with rapid weight gain $[13,14,24-28]$. The reduced insulin sensitivity could either cause impairments in the GH-insulin-like growth factor (IGF)-IGF binding protein (IGFBP) axis or be a consequence of those impairments [24-26].

We have reported previously that continuous low-dose and discontinuous mid-dose and high-dose GH regimens were associated with similar height gain in short SGA children [29]. In the present study, we extend our research and hypothesise that $\mathrm{GH}$-related changes in the metabolic profile will, in these children, be dose-depen- dent, and thus differ according to the GH regimen. For that purpose, we assessed serum fasting levels of leptin, ghrelin, IGF-I, IGFBP-1, lipid profile (high-density lipoprotein (HDL), low-density lipoprotein (LDL) and total cholesterol), glucose and insulin prior to and 12 and 24 months after $\mathrm{GH}$ therapy.

\section{Subjects and Methods}

\section{Subjects}

The study population in this randomised, double-blind, prospective study consisted of 149 short children born SGA (birth weight and/or length below -2 SDS for age and gender according to country-specific standards). Children were recruited at 36 study centres in 8 countries: Czech Republic, Finland, Germany, Israel, Poland, Portugal, Spain and Sweden [29].

Inclusion criteria were: age 3-8 years and pre-pubertal [30]; current height $\leq-2.5$ SDS; height velocity during the last 3 months $\leq 0$ SDS; parental height $\geq-2$ SDS, according to the specific population's mean. Exclusion criteria were: therapy with investigational drugs in the 3 months prior to the study; prior treatment with GH or with any medical product that might interfere with $\mathrm{GH}$ therapy; $\mathrm{GH}$ deficiency ( $\mathrm{GH}$ peak after stimulation $<10$ $\mathrm{ng} / \mathrm{ml}$ ); benign intracranial hypertension; growth retardation due to infection, severe chronic disease, chromosomal abnormalities or nutritional disorders; diabetes; severe arterial hypertension and liver or kidney disease. All local ethics committees/institutional review boards approved the study protocol and written informed consent was obtained from parents.

\section{Methods}

Patients were randomly assigned through a centralised computer system (Novo Nordisk A/S, Copenhagen, Denmark) to double-blind treatment in one of two active GH treatment groups or to a control group that was left untreated in the first year [29]. The two active treatments were continuous low-dose GH therapy (Norditropin $^{\circledR}$ SimpleXx ${ }^{\circledR}$, Novo Nordisk A/S) at $0.033 \mathrm{mg} / \mathrm{kg} /$ day for 2 years (low-dose group) or high-dose GH therapy at 0.100 $\mathrm{mg} / \mathrm{kg} /$ day for a year, followed by a year of observation without treatment (high-dose group). The control group received middose GH therapy at $0.067 \mathrm{mg} / \mathrm{kg} /$ day during the second study year (mid-dose group). GH therapy was delivered daily at bedtime by subcutaneous injection, using the NordiPen ${ }^{\circledR}$ (Novo Nordisk $\mathrm{A} / \mathrm{S}$ ). We previously reported on the growth response to different $\mathrm{GH}$ administration regimens in these patients [29].

\section{Hormonal Assays}

Fasting serum levels of leptin, ghrelin, IGF-I, IGFBP-1, lipids (HDL, LDL and total cholesterol), glucose and insulin were assessed at baseline and at 12 and 24 months. Serum samples were analysed according to the manufacturer's instructions in a central laboratory. Standard laboratory assays were used to assess lipids and glucose and immunoassays were used for leptin, ghrelin, IGFI, IGFBP-1, and insulin. Blood samples were drawn in the morning 
after an overnight fast and immediately separated and stored at $-20^{\circ} \mathrm{C}$ until assayed without freeze/thaw cycles. All samples of 1 patient were assayed on the same day in single determination using kits of the same lot number. The sensitivity of the leptin assay was $0.1 \mathrm{ng} / \mathrm{ml}$. The ghrelin assay detected both octanoylated and des-octonoylated human ghrelin with a sensitivity of $100 \mathrm{pg} / \mathrm{ml}$. The within-assay coefficient of variation was $2.74-4.91 \%$ and the between-assay coefficient of variation was $7.22-8.30 \%$, depending on the concentration of ghrelin in the specimen. IGF-I measurements were standardised according to the assay manufacturer's reference tables and are presented as SDS. For other measurements, the central laboratory's normal reference ranges were used.

The study was conducted from November 2002 until July 2006. Data management was conducted by Novo Nordisk A/S.

\section{Statistical Analyses}

Mean levels \pm standard deviations (SDs) were calculated for all serum biomarkers using 95\% confidence intervals and evaluated with graphical illustrations. Both at 12 and 24 months the change from baseline of the individual metabolic parameters were analysed in an analysis of variance (ANOVA) model with the treatment groups as an effect and the baseline value as a covariate. F-tests for no treatment effect were also performed. Correlation of the change in serum ghrelin levels with the change in IGF-I SDS after 12 months of active treatment was plotted using linear regression. A simple F-test for no correlation was made. In order to validate the findings, the change in serum ghrelin levels was modelled using an analysis of covariance (ANCOVA) model including change in IGF-I SDS and adjusting for sex, treatment dose, and baseline levels of ghrelin, IGF-I SDS, glucose, insulin, leptin and BMI. Significance was set at $\mathrm{p}<0.05$. All analyses were done using SAS software, version 9.1 (SAS Institute Inc., Cary, N.C., USA).

\section{Results}

At study initiation, age (mean $\pm \mathrm{SD}$ ) was $5.5 \pm 1.5$ years, height SDS $-3.1 \pm 0.6$ and height velocity SDS -1.9 \pm 1.7. The mean birth weight was $2.0 \pm 0.6 \mathrm{~kg}$ and mean gestational age $37.3 \pm 3.4$ weeks. Children were randomised into the three treatment groups: low-dose $(\mathrm{n}=$ $51)$, high-dose $(n=51)$ and mid-dose $(n=47) .49 \%$ of patients were female. All study participants were pre-pubertal at study entry and remained pre-pubertal throughout the study period. The main metabolic parameters are summarised in table 1 .

\section{IGF-I and IGFBP-1}

$\mathrm{GH}$ therapy was associated with significant changes in IGF-I SDS (table 1; fig. 1) between treatment groups both at 12 months $(\mathrm{p}<0.0001)$ and at 24 months $(\mathrm{p}<0.0001)$. In the low-dose group, the mean increase in IGF-I SDS levels remained within the reference range ( -2 to 2 SDS), but in the other two groups, IGF-I SDS levels rose above it after a year of active $\mathrm{GH}$ treatment. Upon discontinua- tion of GH therapy in the high-dose group, mean IGF-I SDS declined considerably and fell within the reference range.

In contrast, IGFBP-1 levels declined during active $\mathrm{GH}$ treatment (table 1; fig. 1). Significant changes appeared between treatment groups both at 12 months $(p=0.005)$ and at 24 months $(\mathrm{p}=0.01)$. The mean $( \pm \mathrm{SD})$ declines in IGFBP-1 values for the low-dose, high-dose and mid-dose groups were $-32.6 \pm 67.3,-75.1 \pm 88.2$ and $-68.9 \pm 101$ $\mu \mathrm{g} / \mathrm{l}$, respectively, after 1 year of active treatment, suggesting a dose-dependent effect of GH. At the end of the 2 -year study period after 1 year off therapy, the levels of IGFBP-1 in the high-dose group had risen slightly, but remained below baseline by $-63.8 \pm 81.5 \mu \mathrm{g} / \mathrm{l}$.

\section{Ghrelin and Leptin}

The age-specific reference range for ghrelin is wide (600-1,400 ng/l). It has been shown previously that short children tend to have increased ghrelin levels [31]. Therefore, not surprisingly, ghrelin levels were above the reference range in all study groups at baseline. Within the study period, the changes were clearly different among the treatment groups both at 12 months $(\mathrm{p}<0.0001)$ and at 24 months $(\mathrm{p}=0.0002)$, with a dose-related decrease within the reference range (table 1 ; fig. 1). The mean $( \pm S D)$ decrease following 1 year of active treatment was $-442 \pm 432 \mathrm{ng} / \mathrm{l}$ in low-dose $(\mathrm{p}<0.0001)$, approximately a $26 \%$ decline; $-547 \pm 619 \mathrm{ng} / \mathrm{l}$ in mid-dose $(\mathrm{p}=0.0002)$, approximately a $31 \%$ decline, and $-812 \pm 729 \mathrm{ng} / \mathrm{l}$ in high-dose patients ( $\mathrm{p}<0.0001)$, approximately a $41 \%$ decline. These results were also suggestive of a dose-dependent action of GH. Upon discontinuation of treatment, ghrelin levels rose back to the baseline range $(1,838 \pm 991$ ng/l) in the high-dose group.

The magnitude of increment of IGF-I due to 1 year of active GH therapy significantly correlated with decreasing ghrelin levels ( $p<0.001$; fig. 2). Only the baseline level of ghrelin $(p<0.001)$ and treatment dose $(p=0.036)$ had a statistical adjusting effect on the correlation. None of the other measures had significant adjusting effects (sex: $p=0.92$, baseline IGF-I SDS: $p=0.09$, baseline BMI: $\mathrm{p}=0.58$, baseline glucose: $\mathrm{p}=0.24$, baseline insulin: $\mathrm{p}=$ 0.57 , baseline leptin: $\mathrm{p}=0.12$ ). When adjusting for baseline level of ghrelin and treatment dose, the change of ghrelin was still significantly influenced by change in IGF-I SDS ( $p=0.0016)$ with a $92 \mathrm{ng} / \mathrm{l}$ ghrelin decrease for each increase of 1 SDS of IGF-I.

Leptin changes were significantly different among treatment groups both at 12 months $(\mathrm{p}=0.004)$ and at 24 months $(p=0.002)$. Leptin levels declined in the two 
Table 1. Results for selected metabolic parameters at baseline, 12 months and 24 months stratified by treatment group

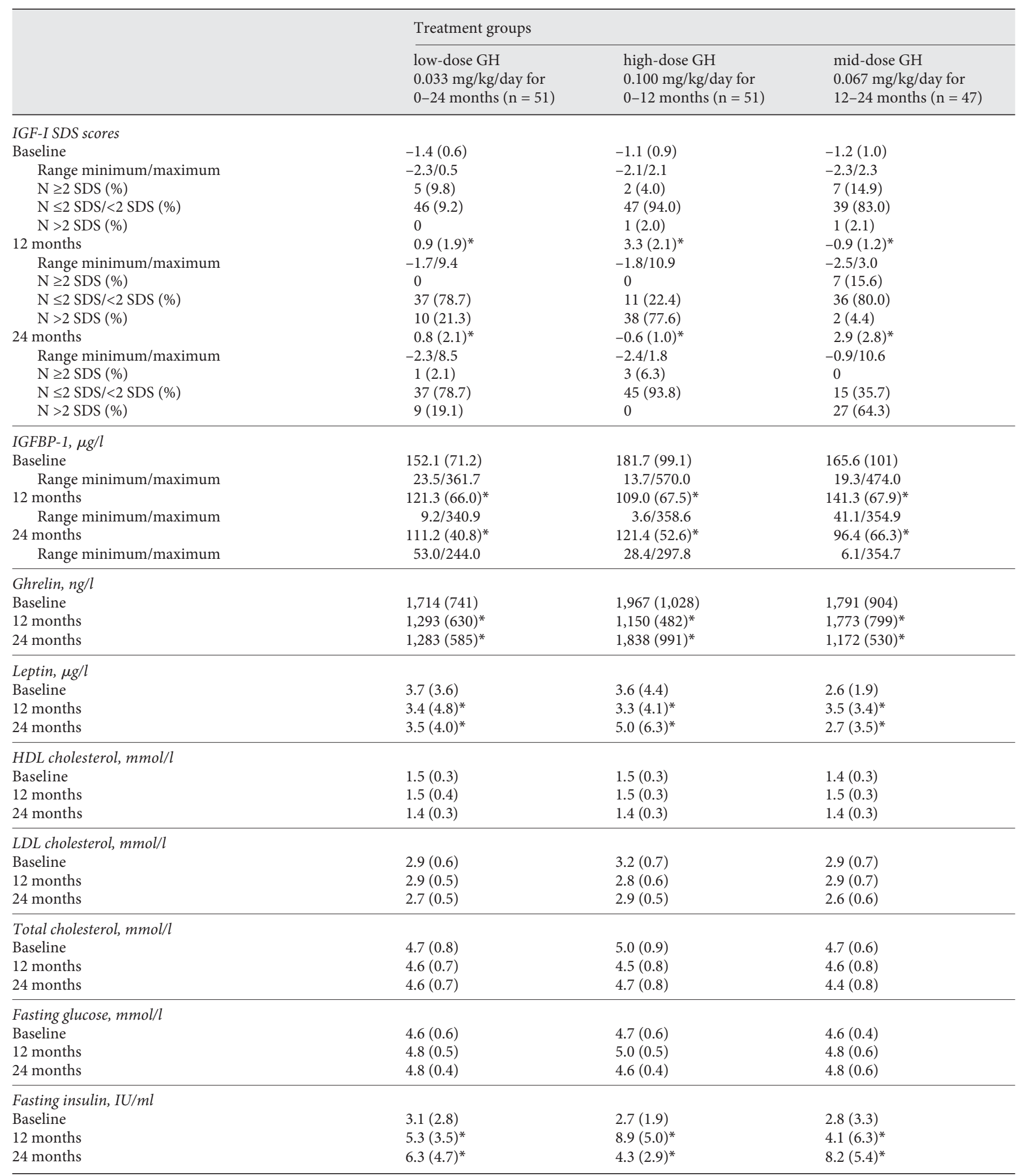

Data are mean $( \pm S D)$, except where range and $\mathrm{n}$ are given. ${ }^{*}$ Significant change among treatment groups $\mathrm{p}<0.05$. 


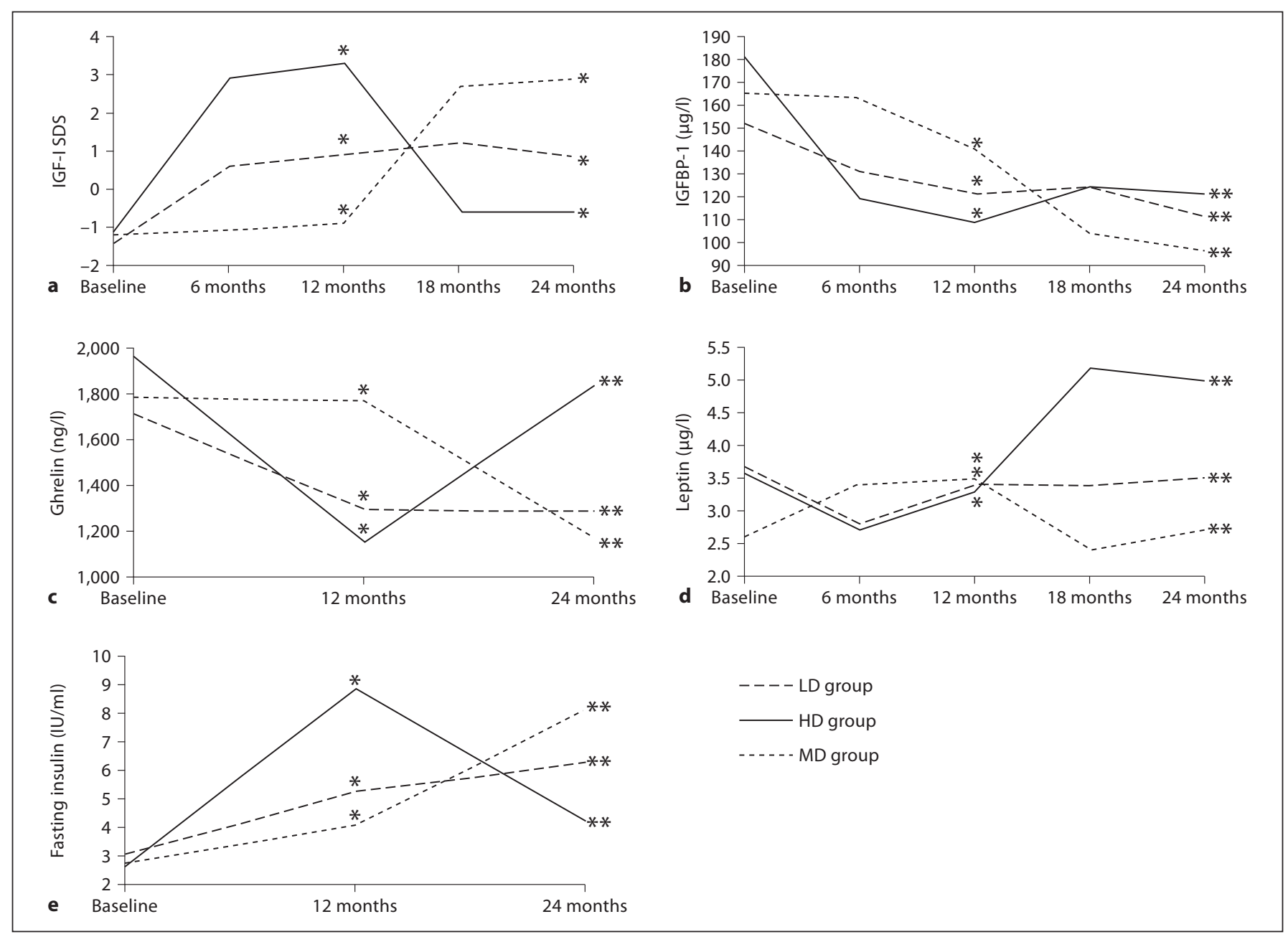

Fig. 1. Dose-dependent changes during the 2-year study period according to treatment group. The low-dose (LD) group received $\mathrm{GH}$ therapy at $0.033 \mathrm{mg} / \mathrm{kg} /$ day for 2 years; the high-dose (HD) group received $\mathrm{GH}$ therapy at $0.100 \mathrm{mg} / \mathrm{kg} /$ day the first year and no treatment the second year, and the mid-dose (MD) group (control) received no treatment the first year and GH therapy at 0.067

groups that received GH therapy in the first year (table 1; fig. 1); in contrast, leptin rose during the first year off therapy in the mid-dose $\mathrm{GH}$, and declined upon $\mathrm{GH}$ start. At the end of the study period, leptin values remained significantly above baseline both in the mid-dose and high-dose subgroups $(0.1 \pm 3.1$ and $1.1 \pm 5.9 \mu \mathrm{g} / \mathrm{l}$, respectively; $\mathrm{p}=0.002$ ).

\section{Lipids}

GH-elicited changes in serum levels of HDL, LDL and total cholesterol were similar and nonsignificant among groups at both 12 and 24 months.

$\mathrm{mg} / \mathrm{kg} /$ day the second year. Data are expressed as mean values and $\mathrm{p}$ values are for mean differences in changes between treatment groups: a IGF-I, ${ }^{*} \mathrm{p}<0.0001$; $\mathbf{b}$ IGFBP- $1,{ }^{*} \mathrm{p}=0.005$ and ${ }^{* *} \mathrm{p}=0.01 ;$ c ghrelin, ${ }^{*} \mathrm{p}<0.0001$ and ${ }^{* *} \mathrm{p}=0.0002 ; \mathbf{d}$ leptin, ${ }^{*} \mathrm{p}=$ 0.004 and ${ }^{* *} \mathrm{p}=0.002$, and $\mathbf{e}$ fasting insulin, ${ }^{*} \mathrm{p}<0.0001$ and ${ }^{* *} \mathrm{p}=0.0005$.

\section{Fasting Glucose and Insulin}

Fasting glucose levels remained within the normal range in all treatment groups throughout the study (table 1). No significant differences among groups could be detected. Fasting insulin levels rose in all groups during active GH treatment, in a dose-dependent fashion (table 1; fig. 1). The changes were different among treatment groups both at 12 months $(\mathrm{p}<0.0001)$ and at 24 months $(p=0.0005)$. All increases remained within the reference range. After active treatment in the high-dose group, insulin levels declined at study end to within $1.7 \pm 3.3 \mathrm{IU} /$ $\mathrm{ml}$ of the baseline measure. 


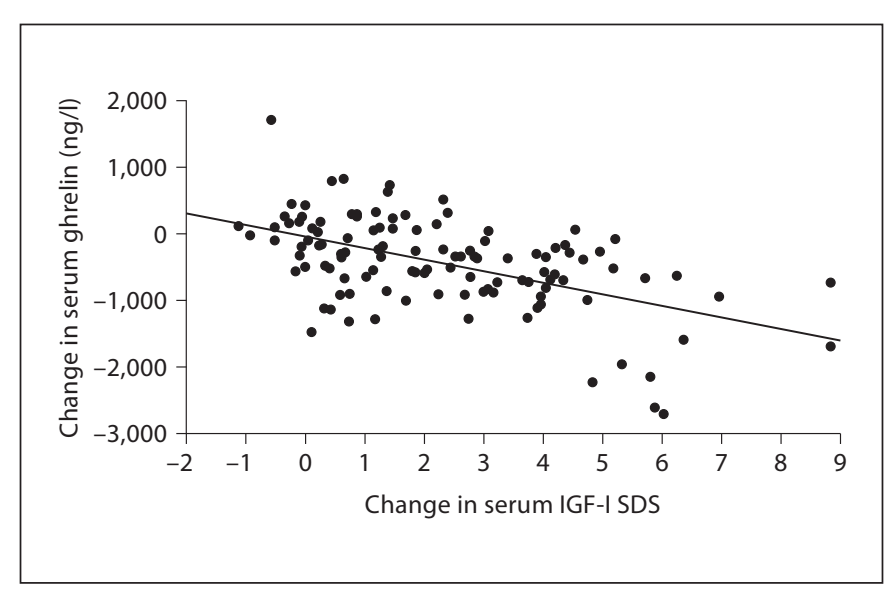

Fig. 2. Correlation between changes in serum ghrelin and IGF-I levels during 1 year of active GH treatment among the three study groups. $\mathrm{p}<0.001$ for the linear relationship.

\section{Discussion}

Despite the well-known association between SGA and long-term metabolic consequences, there have been just a limited number of studies published so far on the metabolic influences of GH therapy in short children born SGA [32-34]. In this comparative, prospective analysis of short pre-pubertalGH-treated SGA children randomised to different treatment regimens, GH treatment induced significant and dose-dependent decreases in ghrelin and leptin levels, both of which are substantially involved in metabolic regulation. We hypothesise that these changes may account for an important part of the impact of $\mathrm{GH}$ therapy on the metabolic profile in these children, namely influencing lipid mobilisation and glucose production through decreased ghrelin and leptin. In the present study, the reverse correlation between IGF-I and ghrelin levels was not influenced by gender or BMI. Only baseline ghrelin and treatment dose affected this relationship.

Reductions in the levels of leptin and ghrelin in the course of GH treatment have been associated with decreases in body fat $[18,35-37]$. Since ghrelin is an appetite stimulant, a decrease in the levels of this hormone may promote a more healthy energy balance in short children born SGA. The reduction in fat mass, reported in other studies [35-37], may be due to the metabolicenhancing effects of $\mathrm{GH}$ on lipolysis and glucose production [37]. The evolutionary development of GH among humans in utilising carbohydrates and protein for fuel in times of energy surplus and switching to the use of lipids in time of scarcity helps to explain the metabolic observations of Engström et al. [37] and Møller and Jørgensen [38]. Our data are consistent with that hypothesis and also with previous data showing an increase in lean body mass and a decrease in fat mass in short SGA children following GH treatment [39]. Recent evidence suggests that spontaneous catch-up growth experienced by SGA infants and children results in a disproportionate increase in body fat instead of lean tissue, particularly abdominal adiposity, raising their risk for insulin resistance, type 2 diabetes, obesity and cardiovascular disease as adults $[13,14,40,41]$. Short SGA children who receive $\mathrm{GH}$ treatment may reach a normalised adult height without the increased risks for overweight and increased fat mass.

Regarding the increase in leptin observed during the first year off therapy in the mid-dose GH treatment group, leptin levels are affected by age, gender, body mass index and pubertal status [42]. Since our study cohort included children aged 3-8 years, one would expect that in both girls and boys leptin would naturally increase in the control group, as indicated in figure 1. When treatment was initiated in the mid-dose group, leptin decreased as in the other groups. The results of this study indicated that leptin rises if untreated, and GH therapy prevents it from increasing.

Consistent with our study's finding of a significant correlation between declining ghrelin levels and rising IGF-I SDS levels ( $p<0.001)$, Engström et al. [37] reported a correlation between these parameters in adults with $\mathrm{GH}$ deficiency. The relationship between ghrelin and IGF-I was attributed to a negative feedback loop of the $\mathrm{GH}-$ IGF-I axis on ghrelin secretion [37] and the reduction in ghrelin was ascribed to the $\mathrm{GH}$-promoting effects on glucose production, lipolysis and, possibly, insulin secretion [37]. Other results from observational cross-sectional, as well as interventional, studies have also suggested a potential inverse relationship between ghrelin and IGF-I $[20,21,43]$. Likewise, our results support the existence of a negative feedback loop of the GH-IGF-I axis in short SGA children who receive GH treatment. However, there may be an additional factor contributing to increasing IGF-I levels with GH administration, besides the ghrelin-GH-IGF-I feedback loop. Boonstra et al. [44] have shown that SGA children treated with GH naturally increase their appetite while on therapy. IGF-I is also influenced by nutritional status [45].

The decline in IGFBP-1 levels is most likely the consequence of the increase in insulin levels observed during periods of active GH treatment. It is well established that 
serum IGFBP-1 levels are controlled by insulin and, to a lesser degree, by glucose [26]. The dose-dependent influence of insulin on IGFBP-1 levels, however, appears to be limited to the duration of GH treatment [34].

The increase in fasting insulin levels observed in this study, while still remaining within normal ranges, is in line with the known acute effect of GH on insulin signalling. The rise in insulin levels reverted upon GH discontinuation, as previously reported [46, 47]. It should be noted that the morning sample for measuring insulin and glucose levels was taken approximately $10-14 \mathrm{~h}$ after the $\mathrm{GH}$ dose. Since maximum serum GH concentrations occur 2-8 h after dose administration [48], it is likely that insulin and glucose levels would decline further throughout the day. Further investigations to determine the 24hour glucose and insulin profiles following GH dosing may be warranted to determine the overall impact of GH therapy on insulin and glucose levels.

In contrast with previous studies that reported $\mathrm{GH}$ induced persistent benefits on lipid profile in short SGA children [5,34], we observed only slight, nonsignificant improvements in total cholesterol and LDL cholesterol levels. It is likely that longer GH treatment is needed to detect significant changes in the lipid profile, and may also explain the persistent benefits observed after treatment is stopped [32].

\section{Conclusion}

In short SGA children, GH treatment appears to reduce ghrelin levels through a negative feedback loop of the GH-IGF-I axis and is associated with beneficial effects on lipolysis and glucose production that also lower levels of leptin, increasing lean body mass and reducing fat mass. Glucose levels remained within normal limits in this study, and the changes in insulin levels were reversible upon treatment discontinuation. As the results suggest that at least some of the GH-induced metabolic changes are dose-dependent, with a tendency to vanish after discontinuation of treatment, $\mathrm{GH}$ administration throughout childhood with carefully selected GH dosages appears to be an advantageous clinical practice in short SGA children. Further research is warranted to clarify the effect of GH treatment on lipid levels and confirm the long-term benefits of $\mathrm{GH}$ on metabolic risks in this population.

\section{Acknowledgements}

The authors would like to thank Mr. Peter Budka and Dr. Catherine Jones (Watermeadow Medical) for their editorial assistance, which was supported by Novo Nordisk A/S. This study was funded by Novo Nordisk A/S.

\section{References}

$>1$ Albertsson-Wikland K, Karlberg J: Natural growth in children born small for gestational age with and without catch-up growth. Acta Paediatr Suppl 1994;399:64-70.

-2 Jaquet D, Collin D, Lévy-Marchal C, Czernichow P: Adult height distribution in subjects born small for gestational age. Horm Res 2004;62:92-96.

3 Czernichow P: Growth hormone treatment strategy for short children born small for gestational age. Horm Res 2004;62(suppl 3):137-140.

-4 Sas T, De Waal W, Mulder P, Houdijk M, Jansen M, Reeser M, Hokken-Koelega A: Growth hormone treatment in children with short stature born small for gestational age: 5 -year results of a randomized, doubleblind, dose-response trial. J Clin Endocrinol Metab 1999;84:3064-3070.

5 Sas TC, Gerver WJ, De Bruin R, Mulder PG, Cole TJ, De Waal W, Hokken-Koelega A: Body proportions during 6 years of GH treatment in children with short stature born small for gestational age participating in a randomised, double-blind, dose-response trial. Clin Endocrinol (Oxf) 2000;53:675-681.
6 Albanese A, Stanhope R: GH treatment induces sustained catch-up growth in children with intrauterine growth retardation: 7-year results. Horm Res 1997;48:173-177.

-7 Bannink EM, van Doorn J, Mulder PG, Hokken-Koelega AC: Free/dissociable insulinlike growth factor (IGF)-I, not total IGF-I, correlates with growth response during growth hormone treatment in children born small for gestational age. J Clin Endocrinol Metab 2007;92:2992-3000.

-8 Rosilio M, Carel JC, Ecosse E, Chaussainon JL: Adult height of prepubertal short children born small for gestational age treated with GH. Eur J Endocrinol 2005;152:835-843.

-9 De Zegher F, Albertsson-Wikland K, Wilton P, Chatelain P, Jonsson B, Löfström A, Butenandt $\mathrm{O}$, Chaussain JL: Growth hormone treatment of short children born small for gestational age: meta-analysis of four independent, randomized, controlled, multicentre studies. Acta Paediatr Suppl 1996;417: 27-31.
10 De Zegher F, Du-Caju MVL, Heinrichs C, Maes M, De Schepper J, Craen M, Vanweser K, Malvaux P, Rosenfeld RG: Early, discontinuous, high dose growth hormone treatment to normalize height and weight of short children born small for gestational age: results over 6 years. J Clin Endocrinol Metab 1999;84:1558-1561.

11 Sas T, Mulder P, Hokken-Koelega A: Body composition, blood pressure, and lipid metabolism before and during long-term growth hormone $(\mathrm{GH})$ treatment in children with short stature born small for gestational age either with or without GH deficiency. J Clin Endocrinol Metab 2000;85:3786-3792.

12 Barker DJ: The developmental origins of chronic adult disease. Acta Paediatr Suppl 2004;93:26-33.

13 Ibáñez L, Lopez-Bermejo A, Suárez L, Marcos MV, Díaz M, de Zegher F: Visceral adiposity without overweight in children born small for gestational age. J Clin Endocrinol Metab 2008;93:2079-2083. 
\14 Ibáñez L, Suárez L, Lopez-Bermejo A, Díaz M, Valls C, de Zegher F: Early development of visceral fat excess after spontaneous catch-up growth in children with low birthweight. J Clin Endocrinol Metab 2008;93: 925-928.

15 Lévy-Marchal C, Czernichow P: Small for gestational age and the metabolic syndrome: which mechanism is suggested by epidemiological and clinical studies? Horm Res 2006; 65(suppl 3):123-130.

-16 Brennan AM, Mantzoros CS: Drug insight: the role of leptin in human physiology and pathophysiology - emerging clinical applications. Nat Clin Pract Endocrinol Metab 2006;2:318-327.

-17 Boguszewski M, Dahlgren J, Bjarnason R, Rosberg S, Carlsson LM, Carlsson B, Albertsson-Wikland K: Serum leptin in short children born small for gestational age: relationship with the growth response to growth hormone treatment. The Swedish Study Group for Growth Hormone Treatment. Eur J Endocrinol 1997;137:387-395.

-18 Boguszewski MCS, de Zegher F, AlbertssonWikland K: Serum leptin in short children born small for gestational age: Dose-dependent effect of growth hormone treatment. Horm Res 2000;54:120-125.

19 Kojima M, Hosoda H, Date Y, Nakazato M, Matsuo H, Kangawa K: Ghrelin is a growthhormone-releasing acylated peptide from stomach. Nature 1999;402:656-660.

20 Camurdan MO, Bideci A, Demirel F, Cinaz P: Serum ghrelin, IGF-I and IGFBP-3 levels in children with normal variant short stature. Endocr J 2006;53:479-484.

-21 Matsuoka H, Hosoda H, Sugawara H, Iwama S, Kim HS, Kangawa K, Sugihara S: Shortterm secretory regulation of ghrelin during growth hormone provocative tests in prepubertal children with various growth hormone secretory capacities. Horm Res 2005; 64:274-279.

-22 Méndez-Ramírez F, Barbosa-Sabanero G, Romero-Gutiérrez G, Malacara JM: Ghrelin in small-for-gestational age newborn babies: a cross-sectional study. Clin Endocrinol (Oxf) 2009;70:41-46.

23 Tschöp M, Smiley DL, Heiman ML: Ghrelin induces adiposity in rodents. Nature 2000; 407:908-913.

-24 Verkauskiene R, Jaquet D, Deghmoun S, Chevenne D, Czernichow P, Lévy-Marchal $\mathrm{C}$ : Smallness for gestational age is associated with persistent change in insulin-like growth factor I (IGF-I) and the ratio of IGF-I/IGFbinding protein-3 in adulthood. J Clin Endocrinol Metab 2005;90:5672-5676.

-25 Woods KA, van Helvoirt M, Ong KK, Mohn A, Levy J, de Zegher F, Dunger DB: The somatotropic axis in short children born small for gestational age: relation to insulin resistance. Pediatr Res 2002;51:76-80.

26 Cutfield WS, Hofman PL, Vickers M, Breier B, Blum WF, Robinson EM: IGFs and binding proteins in short children with intrauter- ine growth retardation. J Clin Endocrinol Metab 2002;87:235-239.

27 Leunissen RWJ, Kerkhof GF, Stijnen T, Hokken-Koelega A: Timing and tempo of firstyear rapid growth in relation to cardiovascular and metabolic risk profile in early adulthood. JAMA 2009;301:2234-2242.

28 Mericq V, Ong KK, Bazaes R, Pena V, Avila A, Salazar T, Soto N, Iniguez G, Dunger DB: Longitudinal changes in insulin sensitivity and secretion from birth to age three years in small- and appropriate-for-gestational-age children. Diabetologia 2005;48:2609-2614.

29 Phillip M, Lebenthal Y, Lebl J, ZuckermanLevin N, Korpal-Szczyrska M, Marques JS, Steensberg A, Jons K, Kappelgaard AM, Ibanez L, European Norditropin SGA Study Group: European multicentre study in children born small for gestational age with persistent short stature: comparison of continuous and discontinuous growth hormone treatment regimens. Horm Res 2009;71:5259.

30 Tanner JM, Whitehouse RH, Cameron N, Marshall WA, Healy MJR, Goldstein H: Assessment of Skeletal Maturity and Prediction of Adult Height, ed 2. London, Academic Press, 1983, chapt 5, pp 38-49.

- 31 Iniguez G, Roman R, Youlton R, Cassorla F, Mericq V: Ghrelin plasma levels in patients with idiopathic short stature. Horm Res Paediatr 2011;75:94-100.

32 Willemsen RH, Willemsen SP, HokkenKoelega AC: Longitudinal changes in insulin sensitivity and body composition of smallfor-gestational-age adolescents after cessation of growth hormone treatment. J Clin Endocrinol Metab 2008;93:3449-3454.

33 Willemsen RH, Arends NJT, Waarde WMBV, Jansen M, van Mil EGAH, Mulder J, Odink RJ, Reeser M, Rongen-Westerlaken C, Stokvis-Brantsma WH, Waelkens JJJ, Hokken-Koelega ACS: Long-term effects of growth hormone $(\mathrm{GH})$ treatment on body composition and bone mineral density in short children born small-for-gestationalage: six-year follow-up of a randomized controlled GH trial. Clin Endocrinol 2007;67: 485-492.

34 Van Dijk M, Bannink EMN, van Pareren YK, Mulder PGH, Hokken-Koelega ACS: Risk factors for diabetes mellitus type 2 and metabolic syndrome are comparable for previously growth hormone-treated young adults born small for gestational age (SGA) and untreated short SGA controls. J Clin Endocrinol Metab 2007;92:160-165.

35 Florkowski CM, Collier GR, Zimmet PZ, Livesey JH, Espiner EA, Donald RA: Low-dose growth hormone replacement lowers plasma leptin and fat stores without affecting body mass index in adults with growth hormone deficiency. Clin Endocrinol (Oxf) 1996;45: 769-773.

36 Janssen YJ, Frolich M, Deurenberg P, Roelfsema F: Serum leptin levels during recombinant human GH therapy in adults with GH deficiency. Eur J Endocrinol 1997;137:650654.

37 Engström BE, Burman P, Holdstock C, Karlsson FA: Effects of growth hormone (GH) on ghrelin, leptin, and adiponectin in GH-deficient patients. J Clin Endocrinol Metab 2003;88:5193-5198.

38 Møller N, Jørgensen JO: Effects of growth hormone on glucose, lipid, and protein metabolism in human subjects. Endocr Rev 2009;30:152-177.

39 Hokken-Koelega A, van Pareren Y, Arends N, Boonstra V: Efficacy and safety of longterm continuous growth hormone treatment of children born small for gestational age. Horm Res 2004;62(suppl 3):149-154.

40 Dulloo AG: Thrifty energy metabolism in catch-up growth trajectories to insulin and leptin resistance. Best Pract Res Clin Endocrinol Metab 2008;22:155-171.

41 Cianfarani S, Germani D, Branca F: Low birthweight and adult insulin resistance: the 'catch-up growth' hypothesis. Arch Dis Child Fetal Neonatal Ed 1999;81:F71-F73.

-42 Garcia-Mayor RV, Andrade MA, Rios M, Lage M, Dieguez C, Casanueva FF: Serum leptin levels in normal children: relationship to age, gender, body mass index, pituitary-gonadal hormones, and pubertal stage. J Clin Endocrinol Metab 1997;82: 2849-2855.

43 Whatmore AJ, Hall CM, Jones J, Westwood M, Clayton PE: Ghrelin concentrations in healthy children and adolescents. Clin Endocrinol (Oxf) 2003;59:649-654.

44 Boonstra VH, Arends NJT, Stijnen T, Blum WF, Akkerman O, Hokken-Koelega ACS: Food intake of children with short stature born small for gestational age before and during a randomized GH trial. Horm Res 2006;65:23-30.

45 Martínez de Icaya P, Fernández C, Vázquez C, del Olmo D, Alcázar V, Hernández M: IGF-1 and its binding proteins IGFBP-1 and 3 as nutritional markers in prepubertal children. Ann Nutr Metab 2000;44:139143.

46 Van Pareren Y, Mulder P, Houdijk M, Jansen M, Reeser M, Hokken-Koelega A: Effect of discontinuation of growth hormone treatment on risk factors for cardiovascular disease in adolescents born small for gestational age. J Clin Endocrinol Metab 2003;88:347353.

47 Hokken-Koelega AC, van Pareren Y, Sas T, Arends N: Final height data, body composition and glucose metabolism in growth hormone-treated short children born small for gestational age. Horm Res 2003;60(suppl 3):113-114.

48 Walvoord EC, de la Peña A, Park S, Silverman B, Cuttler L, Rose SR, Cutler G, Drop S, Chipman JJ: Inhaled growth hormone (GH) compared with subcutaneous GH in children with GH deficiency: pharmacokinetics, pharmacodynamics, and safety. J Clin Endocrinol Metab 2009;94:2052-2059. 